\title{
O RELEVANTE PAPEL DAS CIDADES NA INTEGRAÇÃO REGIONAL SUL- AMERICANA: A REDE MERCOCIDADES COMO VIA PROPÍCIA À RESSIGNIFICAÇÃO DOS ESPAÇOS URBANOS DE FRONTEIRA E AO DESENVOL VIMENTO DA INTEGRAÇÃO FRONTEIRIÇA
}

\section{THE SIGNIFICANT ROLE OF CITIES IN SOUTH AMERICAN REGIONAL INTEGRATION: THE MERCOCIUDADES NETWORK AS MEANS FOR REFRAMIG FRONTIER URBAN SPACES AND DEVELOP BORDER INTEGRATION}

${ }^{1}$ Joséli Fiorin Gomes

\section{RESUMO}

Nas relações internacionais há dois fenômenos relevantes, a integração regional e a paradiplomacia, a atuação internacional de entes subnacionais. Estes elementos, no âmbito sulamericano, manifestam-se na Rede Mercocidades. Esta é organização de municípios formada, inicialmente, para promover a participação de governos locais no MERCOSUL. Em face disso, pela crescente relevância das cidades na cena internacional, vislumbra-se possibilidade de a Rede contribuir para aprofundar a agenda de integração na região, explorando a questão premente da integração fronteiriça. Assim, visa-se a examinar a atuação da Rede junto ao MERCOSUL, para averiguar seu papel quanto à questão fronteiriça no âmbito do bloco.

Palavras-chave: Paradiplomacia, Fronteiras, Integração, Mercocidades, Mercosul

\begin{abstract}
In international relations there are two relevant phenomena, regional integration and paradiplomacy, the international performance of subnational entities. These elements, in the South American context, are manifested in Mercociudades Network. This is an organization of municipalities formed to promote the participation of local governments in MERCOSUR. Given this, the growing relevance of cities on the international stage brings the possibility of the Network to contribute to deepen the regional integration agenda, exploring the pressing issue of border integration. Thus, the aim is to examine its performance within MERCOSUR, to ascertain its role on the border issue in the block.
\end{abstract}

Keywords: Paradiplomacy, Boarders, Integration, Mercociudades, Mercosur

\footnotetext{
${ }^{1}$ Doutora em Direito pela Universidade Federal do Rio Grande do Sul - UFRGS, Rio Grande do Sul (Brasil). Professora convidada Universidade Federal do Rio Grande do Sul - UFRGS, Rio Grande do Sul (Brasil).

E-mail: joselifg@yahoo.com
} 


\section{Introdução}

O mundo atual caracteriza-se pela alta conectividade, a qual promove interações constantes, e até certa sobreposição, entre os âmbitos global, regional e local da atuação políticoeconômica. A recíproca influência entre estas diversas, mas complementares, cenas experimenta-se cotidianamente nas cidades, as quais, hoje, são os locais de maior concentração populacional mundial. Com a crescente urbanização mundial, é nas cidades que demandas compartilhadas globalmente são primeiramente apresentadas e nelas se espera o encontro de soluções. Frente a isso, e pela atual discussão para rever marcos internacionais sobre o desenvolvimento urbano e sustentabilidade, em preparação à Terceira Conferência das Nações Unidas (ONU) sobre Moradia e Desenvolvimento Urbano Sustentável, a ocorrer, em Quito, Equador, em outubro de 2016, os governos locais têm papel essencial na definição e concretização das metas a serem alcançadas nos próximos anos.

Com isso, as cidades tiveram de ampliar seus horizontes de ação, pela busca de investimentos e de qualificação de sua gestão, tornando-se, cada dia mais, novos e essenciais atores das relações internacionais. Isto, então, tem provocado o repensar da diplomacia tradicional, a partir do conceito de paradiplomacia, cunhado para explicar a atuação internacional dos entes subnacionais. Nesse viés, a inserção internacional das cidades, seu envolvimento nas relações internacionais, assume um papel de extrema relevância para a integração regional.

No panorama atual das relações internacionais, a integração regional apresenta-se como parte essencial das agendas de política externa de diferentes países. Na América do Sul, a integração regional, nas últimas décadas, apresentou ampliação de sua agenda, ultrapassando o viés puramente econômico, para inserir preocupações relativas a aspectos políticos, sociais e culturais. Nestes aspectos, insere-se a questão, ainda pouco explorada, da integração fronteiriça, referente às ações coordenadas entre os países envolvidos em blocos regionais com relação a suas fronteiras, a fim de abarcar demandas das populações que ali vivem. Nesse sentido, por envolver as populações fronteiriças, é tema que concerne aos governos locais, responsáveis pelas cidades nas quais estas habitam.

A integração fronteiriça, promovida pelas iniciativas de integração regional desenvolvidas pelos países, implica em reflexos diretos às políticas públicas desenvolvidas pelos governos municipais, ao referir-se à reconstrução e ressignificação dos espaços urbanos fronteiriços pela possibilidade de concretizar a livre circulação de pessoas de diversas nacionalidades e todos os aspectos sociais, culturais, políticos e econômicos que esta 
O Relevante Papel das Cidades na Integração Regional Sul- Americana: A Rede Mercocidades como via Propícia à Ressignificação dos Espaços Urbanos de Fronteira e ao Desenvolvimento da Integração

Fronteiriça

circulação necessariamente traz. Assim, o direito internacional, na vertente do direito da integração regional, decorrente dos blocos regionais, e o direito urbanístico devem traçar diálogo, a fim de que a política externa de um país para a integração regional seja definida a partir construção conjunta com os demais atores necessários à concretização das medidas dela provenientes. Os governos locais, então, passam a ser atores aliados aos governos nacionais e à sua diplomacia, devendo ser considerados e ouvidos na elaboração e tomada de decisões em âmbito internacional e regional.

Os governos municipais vêm, com isso, adquirindo funções relevantes no ambiente internacional, especialmente no que tange à discussão e definição de políticas públicas compartilhadas para a implementação da integração regional. Em face disso, apresenta-se como ator de destaque neste cenário a Rede Mercocidades. Esta foi formada para buscar a participação dos governos locais na integração mercosulina. A importância da participação de governos subnacionais, em especial os governos municipais, na integração regional se dá pelo fato destes governos estarem mais próximos aos problemas e demandas dos cidadãos do que os governos nacionais, parecendo mais aptos a atendê-los. Nesse sentido, a Rede Mercocidades visa a que os governos municipais tornem-se protagonistas deste processo, adquirindo voz e espaço de atuação para melhoria das políticas sul-americanas.

Nesse passo, este trabalho visa a examinar duas questões. A primeira destina-se a perquirir sobre a atuação da Rede Mercocidades, identificando sua relação com o MERCOSUL, tendo em vista que foi criada para favorecer a participação das cidades junto a este bloco regional. A partir disso, a segunda questão refere-se a averiguar o papel da Rede em termos de desenvolvimento da temática da integração fronteiriça junto ao MERCOSUL, em razão de visar ao aprofundamento do protagonismo das cidades na integração regional sul- americana e as consequências disto para a reconstrução e ressignificação dos espaços urbanos. É o que se tratará a seguir.

\section{O exercício da paradiplomacia na integração regional sul-americana: a Rede Mercocidades e suas relações com o MERCOSUL}

A constante interação entre os diferentes âmbitos da vida em sociedade, como visto nas palavras introdutórias, é sentida cotidianamente nas cidades, o que provoca a estas a se lançarem, cada dia mais, a participar das relações internacionais. A diplomacia, então, tem que se adaptar aos novos tempos, já que a ideia de que as relações internacionais apenas são realizadas pelo e para os governos nacionais centrais tornou-se obsoleta (TAVARES, 2013). 
Em função disso, surge o fenômeno da paradiplomacia ${ }^{1}$. Segundo Fronzaglia, esta pode ser caracterizada como

(...) o conjunto de atividades desenvolvidas pelas unidades subnacionais - de maneira isolada ou conjunta - conforme seu grau de autonomia e que visam sua inserção internacional podendo ser complementares, paralelas ou conflitantes com a diplomacia conduzida pelo governo central. (FRONZAGLIA, 2004, p. 50)

Frente a isso, trata-se de processo de atuação de entes subnacionais ${ }^{2}$ em que interesses e demandas regionais ou locais, de cunho político, econômico e cultural são estabelecidos de modo global, trazendo-lhes maior legitimidade e a possibilidade de encontrarem novos parceiros no âmbito internacional. Então,

\begin{abstract}
A paradiplomacia pode ser definida como o envolvimento de governo subnacional nas relações internacionais, por meio do estabelecimento de contatos, formais e informais, permanentes ou provisórios ('ad hoc'), com entidades estrangeiras públicas ou privadas, objetivando promover resultados socioeconômicos ou políticos, bem como qualquer outra dimensão externa de sua própria competência constitucional. (PRIETO, 2004, p. 252)
\end{abstract}

Nesse viés, a inserção internacional das cidades tem papel relevante para a concretização da integração regional. Esta objetiva fortalecer os países, mediante cooperação econômica, política, social e cultural, ao promover o desenvolvimento e a melhoria da qualidade de vida das suas populações. Parece ser este o caso do MERCOSUL. Para que as decisões tomadas no bloco pudessem ser influenciadas pelos governos locais, criou-se, em 1995, a Rede Mercocidades.

A Rede Mercocidades é uma organização de cooperação descentralizada ${ }^{3}$, formada pelos governos locais da região sul-americana, sendo, atualmente, composta por 307 (trezentas e sete) cidades da Argentina, Brasil, Paraguai, Uruguai, Venezuela, Bolívia, países membros do MERCOSUL, e de Chile, Colômbia e Peru, países associados ao bloco. A Rede visa a proporcionar a inserção das cidades sócias no processo de integração regional do

\footnotetext{
${ }^{1}$ Segundo Duchacek, a paradiplomacia envolve apenas os assuntos de low politics, não se referindo a iniciativas dos governos federados sobre temas de segurança nacional. Nesse passo, o autor a identifica como microdiplomacia, em oposição à macrodiplomacia, que consistiria na diplomacia tradicional dos governos centrais a respeito das questões estratégicas do país (1990, p. 18). No mesmo sentido, Rodrigues refere-se ao fenômeno como "política externa federativa", sustentando que o enfoque recai sobre os interesses e necessidades locais (RODRIGUES, 2004).

${ }^{2} \mathrm{O}$ termo é utilizado pela literatura especializada de modo majoritário, buscando identificar os governos dos Estados e Municípios da federação brasileira, assim como outras figuras políticas congêneres, presentes na organização dos demais Países, diferenciando-as dos governos centrais destes. No entanto, há aqueles, como Castelo Branco e Prazeres, que entendem que seria mais apropriado tecnicamente, para tratar do fenômeno da paradiplomacia e dos entes não centrais, utilizar o termo "subestatais" em vez de "subnacionais", para respeitar a distinção entre Estado e Nação. (CASTELO BRANCO, 2007, p. 56; PRAZERES, 2004, p. 283).

3 Cooperação horizontal ou descentralizada trata-se da relação substancial colaborativa entre governos subnacionais de diferentes países, com vistas ao desenvolvimento local sustentável, o que implica em algumas formas de trocas e suportes conduzidas por estas instituições ou outros atores locais entre si. (ANDRADE E BARROS, 2010, p. 6-10; HAFTECK, 2003, p. 336).
} 
O Relevante Papel das Cidades na Integração Regional Sul- Americana: A Rede Mercocidades como via Propícia à Ressignificação dos Espaços Urbanos de Fronteira e ao Desenvolvimento da Integração

Fronteiriça

MERCOSUL, bem como em outros foros internacionais. Nesse sentido, objetiva fomentar o desenvolvimento de ações, programas e projetos de interesse intermunicipal que se relacionem ao processo de integração. Permite, com isso, o intercâmbio de experiências e informações entre as cidades associadas, a fim de qualificar a prestação de serviços e a infraestrutura urbana, em prol do desenvolvimento e melhoria das condições de vida nas cidades (MERCOCIUDADES, 2016). Portanto, trata-se de exemplo do fenômeno da paradiplomacia na integração regional sul-americana.

Diante disso, a Rede é organizada numa estrutura que conta com diversos órgãos. O principal destes é a Assembleia Geral, para deliberação e direção da Rede, constituída pelos chefes de governo das cidades, a qual se reúne anualmente. Para auxiliá-la há o Conselho, integrado por oito cidades dos países membros do MERCOSUL e quatro cidades dos países associados. Para representar a Rede, há a Presidência, antes chamada, até novembro de 2015, de Secretaria Executiva, que colabora com os demais órgãos, convocando e presidindo as suas reuniões. Em cada período, a cidade que a exerce segue um plano de trabalho aprovado na Cúpula anual da Rede e seu mandato é de um ano, a partir da reunião da Assembleia Geral. Até o final de 2016, é exercida pela cidade de São Paulo, Brasil. (MERCOCIUDADES, 2016).

Junto desta, atua a Direção Executiva, organismo de direção nos trabalhos de Coordenação da Rede. Compete-lhe definir a política geral e as estratégias de atuação da Rede e das suas Unidades Temáticas, exercer as atividades inerentes à gestão administrativa e financeira da entidade, coordenar o Colegiado de Coordenadores das Unidades Temáticas e elaborar e executar o orçamento e o plano de trabalho da Rede. A referida Direção é formada pela Presidência, pelas Vice-Presidências Temáticas, pela Comissão Diretiva e pelo(a) Secretário(a) Executivo(a). (MERCOCIUDADES, 2016).

Às Vice-Presidências Temáticas compete, ao participarem da referida Direção Executiva, promover a Rede junto aos governos locais da região, auxiliar o(a) Presidente(a) nas atividades da Rede; coordenar e mobilizar as cidades-membro da Rede, coordenadoras ou integrantes das Unidades Temáticas afeitas ao seu tema e promover junto às cidades membro o tema do qual é responsável. Há cinco Vice-Presidências Temáticas, a de Relações Institucionais, a de Desenvolvimento Urbano Sustentável e Mudança Climática, a de Integração Social, a de Economia Urbana e a de Integração Fronteiriça. Em 2016, estas instâncias estão sendo exercidas, respectivamente, pelos municípios de Canoas (Brasil), 
Rosario (Argentina), Lo Prado (Chile), Montevidéu (Uruguai) e Porto Alegre (Brasil). (MERCOCIUDADES, 2016).

Por sua vez, a Comissão Diretiva presta apoio nas atividades de coordenação da Rede. É composta por três cidades, a que exerce a Presidência (São Paulo, que a exerce durante 2015/2016), a que a exerceu no período imediatamente anterior (Rosario, Argentina, que a exerceu durante 2014/2015) e a que será a próxima a exercê-la (Santa Fé, Argentina, cidade eleita para exercê-la em 2016/2017). O(A) Secretário(a) Executivo(a) é responsável pela gestão da Rede e por auxiliar seus trabalhos, segundo orientação da Diretoria Executiva. É designado(a) pela Presidência da Rede. (MERCOCIUDADES, 2016).

Como órgão auxiliar da Direção Executiva, há, ainda, a Secretaria Técnica Permanente, com sede em Montevidéu, Uruguai. Esta objetiva desenvolver a memória institucional da Rede, apoiar e assessorar o trabalho técnico e administrativo da Presidência e Direção Executiva, acompanhar temas e debates sobre o processo de integração mercosulino e manter o contato com a Secretaria do MERCOSUL. (MERCOCIUDADES, 2016).

Ademais, dentre os órgãos da Rede, deve-se destacar suas 15 (quinze) Unidades Temáticas (UT). As Unidades Temáticas dedicam-se aos seguintes temas: Ambiente e Desenvolvimento Sustentável; Autonomia, Gestão e Financiamento Municipal; Ciência, Tecnologia e Capacitação; Cooperação internacional; Cultura; Esportes; Desenvolvimento Econômico Local; Desenvolvimento Social; Desenvolvimento Urbano; Educação; Gênero e Município; Juventude; Planificação Estratégica; Segurança Cidadã; Turismo e Integração Fronteiriça. No âmbito de algumas destas UT, há, ainda, 6 (seis) grupos e comissões de trabalho. Os grupos de trabalho são os de Cooperação Descentralizada (junto à UT de Cooperação Internacional), Esportes (junto à UT de Cultura), e de Incapacidades e Inclusão (junto à UT de Desenvolvimento Social), enquanto as Comissões são de Economia Social e Solidária e de Fomento de Negócios (junto à UT de Desenvolvimento Econômico Local) e de Direitos Humanos (junto à UT de Desenvolvimento Social). (MERCOCIUDADES, 2016).

Estas UT, bem como seus respectivos GT e Comissões, discutem temas e realizam ações de interesse local e repercussão internacional. Permitem a troca de experiências entre as cidades, para ampliar o seu desenvolvimento econômico e social. Contam com a Coordenação de uma das cidades sócias e a subcoordenação de outras destas, realizando reuniões periódicas ao ano, para tratar das atividades pertinentes às suas temáticas que se desenvolvem em cada município participante. (MERCOCIUDADES, 2016). 
O Relevante Papel das Cidades na Integração Regional Sul- Americana: A Rede Mercocidades como via Propícia à Ressignificação dos Espaços Urbanos de Fronteira e ao Desenvolvimento da Integração

Fronteiriça

Ao possuir órgãos especializados para expressar os interesses e demandas municipais, a Rede necessitava ter representação mediante uma estrutura jurídicoadministrativa no MERCOSUL. A Rede, com isso, apresentou demanda em face do bloco para criação de uma instância institucional para representação dos governos locais e regionais. Para tanto, estabeleceu-se, em 2004, o Foro Consultivo de Municípios, Estados Federados, Províncias e Departamentos do MERCOSUL (FCCR) (MERCOSUL, 2014). Este órgão consultivo foi criado pela Decisão n. 41/2004 do órgão superior Conselho Mercado Comum (CMC) (MERCOSUL, 2014), estando atrelado ao Grupo Mercado Comum (GMC), órgão executivo do MERCOSUL. Sua finalidade é estimular o diálogo e a cooperação entre as autoridades locais, tendo competência para propor medidas de coordenação de políticas para a promoção do bem-estar e melhoraria da qualidade de vida dos habitantes da região, bem como formular recomendações ao GMC.

Este órgão é formado pelo Comitê de Municípios (COMUM) e pelo Comitê de Estados Federados, Províncias e Departamentos (CEFPD), bem como por uma Coordenação Geral, composta por Coordenadores Nacionais dos países do bloco MERCOSUL, 2004). Conta, ainda, com uma Secretaria Técnica Permanente, também de representantes nacionais (MERCOSUL; FCCR, 2014). O COMUM, por disposição transitória do Regimento Interno do FCCR, é presidido pela Secretaria Executiva da Mercocidades ${ }^{4}$.

Desse modo, é por este órgão que a Rede pode estabelecer o diálogo com o MERCOSUL, enviando-lhe recomendações. Por um lado, isto legitima a Rede como ator no processo de integração mercosulino (DE MATOS, STEFFEN, 2012, p. 37). Por outro, o caráter ainda consultivo deste órgão junto à estrutura institucional do MERCOSUL não garante que as recomendações enviadas serão adotas pelos órgãos decisórios do bloco e, assim, transformadas em normativa deste, o que dificulta um maior impacto da atuação da rede para a tomada de decisões do bloco regional.

Mas esta participação traz outras oportunidades para que a Rede tenha influência na integração regional junto às suas cidades sócias. Uma delas é a possibilidade de o FCCR, como órgão do MERCOSUL, apresentar projetos de desenvolvimento regional junto ao Fundo de Convergência Estrutural do MERCOSUL (FOCEM) ${ }^{5}$, os quais podem ser

\footnotetext{
${ }^{4}$ Segundo o art. 27, do Regimento Interno do FCCR, "até dezembro de 2008, a Coordenação do Comitê de Municípios estará a cargo do governo local que exerça a Secretaria Executiva da Rede de Mercocidades". Contudo, até a finalização deste artigo, não havia se concretizado revisão ou reforma do referido Regimento para estabelecer, definitivamente, a representação dos governos municipais, mantendo-se a Secretaria Executiva da Rede, ainda temporariamente, no cargo. (MERCOSUL; FCCR, 2014).

${ }^{5}$ O Fundo para a Convergência Estrutural do MERCOSUL (FOCEM) foi criado pela Decisão CMC No 45/04. É um fundo destinado a financiar programas para promover a convergência estrutural; desenvolver a
} 
originados de propostas trazidas pela Rede no comando do COMUM. Para tanto, é preciso reforçar a influência política do referido órgão nas decisões tomadas pelo FCCR, a fim de que impulsione as propostas apresentadas pelas cidades.

Ainda, oportunidades de participação relevante para a Rede junto ao MERCOSUL se referem a laços estabelecidos com outros órgãos do bloco. Exemplo disso é o Convênio firmado entre a Rede e o Instituto Social do MERCOSUL (ISM) ${ }^{6}$, que visa à cooperação em pesquisas, análise, promoção e difusão de processos e políticas de fortalecimento da integração, pela redução de assimetrias entre os Estados membros do bloco e pelo desenvolvimento humano integral, com articulação das políticas sociais. Também é exemplo disso, a aproximação que vem se estabelecendo entre a Rede e a Unidade de Apoio à Participação Social do MERCOSUL (UPS), órgão do bloco que busca fortalecer os mecanismos de participação social em sua estrutura. A Rede e a UPS, em 2014, assinaram convênio, a fim de que esta possa afiançar os laços daquela com os espaços do bloco. Este convênio aguarda aprovação do Grupo Mercado Comum do MERCOSUL para ser, então, aprovado pelas instâncias da Rede. (MERCOCIUDADES, 2015).

Frente a isso, a Rede tem encontrado espaços institucionais junto ao MERCOSUL para tentar, pela sua atuação, trazer reflexos das demandas municipais para a condução das atividades do bloco. Contudo, estes espaços, como não possuem competência decisória e normativa junto ao bloco, ainda muito atrelado às presidências e chancelarias dos Estados- partes e associados, possuem impactos reduzidos para a tomada de decisões do MERCOSUL. É preciso, portanto, fortalecer politicamente tais espaços, para que mudanças mais concretas possam ser operadas, a fim de garantir um papel mais relevante aos governos locais no bloco.

Isto é especialmente importante no que tange a um dos temas que tem sido objeto de discussões no seio do MERCOSUL nos últimos anos, qual seja a questão da integração fronteiriça. Segundo Sausi e Oddone (2015, p. 3), a integração regional não coloca fim às fronteiras nem às interações nestas ocorridas, mas as redimensiona, trazendo-lhes maior visibilidade. Nesse sentido, é preciso verificar como a questão transfronteiriça vem sendo tratada no âmbito do MERCOSUL, a fim de compreender que papel podem exercer as cidades

competitividade; promover a coesão social e apoiar o funcionamento da estrutura institucional e o fortalecimento do processo de integração. (MERCOSUL; FOCEM, 2014).

${ }^{6}$ O Instituto Social do MERCOSUL (ISM) é um órgão técnico-político, estabelecido em 2007 (CMC/DEC N ${ }^{\circ}$ 03/07), como resultado da iniciativa da Reunião de Ministros e Autoridades de Desenvolvimento Social do MERCOSUL (RMADS). Efetua pesquisas sobre políticas sociais e implementação de linhas estratégicas para consolidar a dimensão social do bloco e realiza iniciativas que contribuam à redução das assimetrias sociais entre os Estados Partes e para promoção do desenvolvimento humano integral. (MERCOSUL; ISM, 2014). 
O Relevante Papel das Cidades na Integração Regional Sul- Americana: A Rede Mercocidades como via Propícia à Ressignificação dos Espaços Urbanos de Fronteira e ao Desenvolvimento da Integração

Fronteiriça

para sua realização, e, com isso, apontar no que pode a Rede Mercocidades, como representante dos municípios junto ao bloco, contribuir. É o que segue.

\section{A questão fronteiriça na integração regional mercosulina: a Rede Mercocidades como mediadora viável para impulsionar a ressignificação dos espaços urbanos de} fronteira

O MERCOSUL, enquanto processo de integração regional, refere-se intrinsecamente à questão transfronteiriça. Isso se deve, segundo Losada e Sadeck, ao fato de as fronteiras apresentarem um papel essencial no cenário globalizado, pois representam os loci naturais para a realização de programas e projetos de cooperação, seja bi ou multilateral, e de integração, para aproximação de países. (LOSADA; SADECK, 2015, p. 41).

Isto é visível em razão de que, ainda que, inicialmente, o foco do bloco tenha se adstrito a questões comerciais, a partir do final da década de 1990 e início dos anos 2000, a agenda da integração regional sul-americana passou a abarcar novas questões, em decorrência do "novo ciclo político" (BERMUDEZ TORRES, 2011, p. 121), que promoveu a renovação política e ideológica dos governos nacionais sul-americanos. Nesse viés, houve o relançamento do MERCOSUL ${ }^{7}$, que, de um bloco voltado à integração apenas econômica- comercial, passa a abarcar agendas de cooperação em temas como democracia, direitos humanos, educação, cultura, fronteiras, entre outras. Então, o MERCOSUL, ao orientar-se pela proposta de maior aproximação, através de interesses convergentes entre seus membros, passa a buscar a construção de um espaço de interdependência entre estes, permitindo a inclusão de outras discussões no seio de suas instâncias decisórias (ALMEIDA PRADO, 2015 , p. 56,63$)$.

Com isso, de acordo com Almeida Prado, houve “...a criação de grupos de trabalho e instituição de órgãos distintos para atender à crescente demanda de diálogo intrabloco nos mais variados temas" (ALMEIDA PRADO, 2015, p. 63). Dentre estes temas, inseriu-se a questão fronteiriça. Foi nessa conjuntura que se criou, em 2002, mediante a Decisão CMC n. 05/2002, o Grupo Ad Hoc sobre Integração Fronteiriça (GAHIF), cujo objetivo seria propiciar a melhoria da qualidade de vida das populações, mediante a elaboração de propostas de instrumentos normativos para facilitar as relações entre as comunidades transfronteiriças,

\footnotetext{
${ }^{7}$ Em 2000, os Estados membros do bloco reuniram-se em Buenos Aires e acordaram sobre uma série de medidas visando revigorá-lo e redirecioná-lo, com ênfase na consolidação da união aduaneira, com vistas ao avanço ao mercado comum, no desenvolvimento das relações externas do bloco na região e, principalmente, esforços de maior coordenação nos planos político e social. (VAZ, 2000.p. 3-4).
} 
tanto em aspectos comerciais como em assuntos ligados à saúde, educação, segurança, migração, trabalho, transporte, desenvolvimento econômico, dentre outros, para impulsionar a integração entre elas. (MERCOSUL, 2014).

Conforme Sausi e Oddone (2015, p. 5), a constituição do GAHIF resultou de negociação frustrada solicitada pelo Brasil para assegurar a livre circulação de pessoas nas regiões fronteiriças. Primariamente, buscava-se que este elaborasse um "Estatuto das Fronteiras do MERCOSUL”. Ainda neste momento, o Brasil propôs, igualmente, a extensão da qualidade de "natural fronteiriço", que aplicava ao Uruguai com base no "Acordo para Permissão de Residência, Estudo e Trabalho dos Nacionais Fronteiriços" a outras regiões do MERCOSUL. Contudo, os negociadores - em especial os paraguaios - preferiram optar por vias bilaterais de articulação.

Nesse passo, o GAHIF aparentou apresentar pouca efetividade no momento de sua instalação no bloco. Mas, segundo Almeida Prado,

\begin{abstract}
Apesar de pouco dinamismo inicial, alguns temas relevantes ao aprofundamento do processo de integração foram debatidos no grupo. Exemplo disso é o Anteprojeto de Acordo sobre Localidades Fronteiriças Vinculadas, que visa [a] melhorar a qualidade de vida da população de fronteira em termos econômicos, de trânsito, de regime de trabalho, de acesso aos serviços públicos e de educação. (ALMEIDA PRADO, 2015, p. 64).
\end{abstract}

A despeito deste exemplo, entretanto, o GAHIF, ainda existente, apresentou, ao longo de seus treze anos de vigência, poucos avanços (ALMEIDA PRADO, 2015, p. 64). De acordo com Sausi e Oddone (2015, p. 5), as poucas reuniões realizadas ocorreram na ausência de qualquer representação das populações fronteiriças, pois somente os governos nacionais participaram, sem consultar ou chamar a participar quaisquer governos subnacionais, tratando a cooperação fronteiriça mediante a lógica típica do bloco, em caráter "....absolutamente topdown”. Isso ocorre porque, no seio do MERCOSUL, pela sua estrutura intergovernamental, as deliberações são realizadas de modo "vertical e hierarquizado" (ALMEIDA PRADO, 2015, p. 65), ainda centrado na diplomacia tradicional.

Os entes subnacionais possuem, todavia, um espaço de representação junto ao bloco, o anteriormente mencionado FCCR. Neste, a integração fronteiriça faz parte do espectro de discussões. Em face disso, estabeleceu-se em seu âmbito o Grupo de Trabalho de Integração Fronteiriça (GTIF), em 2008, para promover estudos e seminários sobre o tema, bem como envolver os membros do bloco no debate das questões fronteiriças, sob a perspectiva das entidades subnacionais (MERCOSUL; FCCR, 2015; ALMEIDA PRADO, 2015, p. 64-65). 
O Relevante Papel das Cidades na Integração Regional Sul- Americana: A Rede Mercocidades como via Propícia à Ressignificação dos Espaços Urbanos de Fronteira e ao Desenvolvimento da Integração

Ademais, a integração fronteiriça foi eleita como um dos eixos de seu plano de ação atual (MERCOSUL; FCCR, 2015).

No entanto, a eficácia do FCCR para a determinação das políticas adotadas é pequena, em função de seu caráter meramente consultivo, como visto na seção anterior. Com isso, também o impacto do GTIF foi reduzido, restando este, até bem pouco tempo, inerte. O grupo apenas foi reativado recentemente, durante a $45^{\mathrm{a}}$ Reunião dos Coordenadores Nacionais do FCCR, realizada no seio da Cúpula do MERCOSUL, ocorrida em Brasília, em 15 de julho de 2015, para construir uma agenda integrada para o fortalecimento e desenvolvimento desses territórios. (BRASIL; PORTAL FEDERATIVO, 2015). Em face disso, é necessário buscar o fortalecimento político do GTIF e do FCCR, a fim de que os trabalhos ali realizados e as recomendações disto resultantes venham a ser realmente acatadas pelo GMC e pelo CMC.

Para tanto, a Rede Mercocidades pode exercer um papel relevante. Isso porque a inserção de cidades dos países membros e associados do bloco em uma Rede, tal qual a Mercocidades, permite-lhes maior aproximação e, com isso, capacitação para a cooperação descentralizada regional e promoção de melhores e mais visíveis oportunidades de realiza-la. Ou seja, uma Rede organizada de relações, ao conectar as cidades, promove maior articulação entre seus governos, gerando possibilidades maiores de gestão compartilhada e de cooperação entre elas, bem como melhores condições expor suas demandas aos governos centrais responsáveis pela condução do bloco regional. Com isso, a Rede oferece-lhes a via adequada para concretizar a integração fronteiriça, pois fortalece os laços políticos e viabiliza ações reais de desenvolvimento dos territórios vizinhos. Assim, segundo Garcia (2013/2014, p. 23),

\footnotetext{
É através da criação de redes de cooperação entre governos locais que os municípios vêm implementando ações de complementaridade entre as cidades de ambos os lados da fronteira, eliminando barreiras alfandegárias e migratórias, com o objetivo de promover, com suas práticas, a verdadeira integração de zonas e regiões fronteiriças [...].

Para que se possa avançar cada vez mais, há que se promover a eliminação de obstáculos, estabelecendo a cooperação transfronteiriça em todos os aspectos necessário para o desenvolvimento destas áreas, buscando-se implantar um novo conceito de fronteira, dentro de um processo de integração que fortaleça o desenvolvimento e ultrapassem as restrições impostas pelas regras jurídicas vigentes.
}

A fim de estimular maiores diálogo e ações entre os municípios sócios, bem como para atrair a participação de novos membros, por entender-se pela extrema relevância da questão fronteiriça para a integração regional e de seu parco desenvolvimento no seio mercosulino na atualidade, a Rede criou, em 2013, durante a sua XVIII Cúpula, realizada em Porto Alegre, a UT de Integração Fronteiriça, coordenada, naquele momento, pela cidade de Bagé, uma cidade fronteiriça, em conjunto com a Secretaria Executiva da Rede 
(MERCOCIUDADES, 2014). Esta UT vem funcionando como espaço de discussão dos problemas das cidades de fronteira, visando a ampliar a repercussão das demandas locais nos mais diversos aspectos, como saúde, educação, infraestrutura, transporte, esgotos, etc., envolvendo governos e sociedades civis locais, buscando a articulação com órgãos das administrações estaduais, departamentais, provinciais e nacionais, para debate coletivo de projetos para estas regiões, relativos a arranjos produtivos, qualificação profissional, capacitação para gestão e empreendedorismo, orientação quanto à obtenção de recursos, valorização e divulgação da cultura local, integração das ações de saúde e ensino bilíngue, entre outras questões (GARCIA, 2013/2014, p. 23).

Nesse passo, durante 2014, a UT, mediante sua coordenação e por outras cidades sócias da Rede que dela participam, esteve presente, promovendo discussões e ações de cooperação, em diversos eventos importantes relativos à temática da integração fronteiriça. Por exemplo, participou da reunião do Comitê Binacional de Intendentes, Prefeitos e Alcaldes da Fronteira Brasil-Uruguai e do $2^{\circ}$ Encontro das Cidades da Faixa de Fronteira do Rio Grande do Sul, bem como realizou oficina da Rede durante o Seminário Internacional de Regiões de Fronteiras, ocorrido em Foz do Iguaçú, organizado pela Secretaria de Assuntos Federativos da Presidência da República brasileira, que objetivou debater a integração sul- americana, com ênfase no MERCOSUL (GARCIA, 2013/2014, p. 23-24). Com isso, a Rede, através desta UT, propôs eixos de atuação para a integração fronteiriça, envolvendo cooperação e gestão conjunta de projetos para desenvolvimento socioeconômico e para qualificação da prestação de serviços públicos, cooperação e gestão conjunta das questões de acessibilidade, de território, ambientais e de prevenção de riscos de catástrofes, e a assistência técnica para capacitação para elaboração de projetos e acesso a financiamentos internacionais destinados à implementação de projetos de integração fronteiriça. (GARCIA, 2013/2014, p.

24-25)

Ademais, a UT, em conjunto com o FCCR e o GTIF do MERCOSUL, realizou, em Porto Alegre, entre 24 e 25 de setembro de 2015, a primeira reunião do referido Grupo de Trabalho. Neste apresentou-se proposta para a criação das chamadas "MERCORREGIÕES", como espaços de cooperação transfronteiriça, referente ao estabelecimento de ações coordenadas entre autoridades subnacionais (locais e regionais), com apoio dos governos nacionais, para melhoria de serviços públicos mediante consórcios públicos. A proposta será enviada, como sugestão de nova legislação mercosulina, pelo FCCR ao Conselho Mercado Comum (CMC), órgão decisório do MERCOSUL. (MERCOSUL; FCCR, 2015). 
O Relevante Papel das Cidades na Integração Regional Sul- Americana: A Rede Mercocidades como via Propícia à Ressignificação dos Espaços Urbanos de Fronteira e ao Desenvolvimento da Integração

Fronteiriça

Além destas ações, a Rede Mercocidades, durante a gestão de Porto Alegre em sua então Secretaria Executiva (hoje substituída pela Presidência), em 2014, apresentou à Força- Tarefa Global de Governos Locais e Regionais para a Agenda Pós-2015 visando a Habitat III (Global Taskforce of Local and Regional Governments for Post-2015 Agenda towards Habitat $I I I)^{8}$ um documento de referência com as contribuições sugeridas pelas cidades sul- americanas por ela representadas para as discussões e decisões a serem tomadas durante a Conferência Habitat III da ONU em 2016 e para suas atividades preparatórias realizadas em

2015. Neste documento, a Rede defende que, em face da necessidade de fortalecimento dos governos locais e da participação cidadã para o desenvolvimento urbano global, no caso de cidades inseridas em países envolvidos em processos de integração regional, deve se considerar evidente que isto somente pode se dar mediante a redefinição do conceito de fronteiras. Nesse passo, a Rede sustenta ser preciso colocar em prática ações de aproximação das cidades vizinhas, colocando-as como caminhos para a livre circulação de pessoas, bens, serviços e capitais nos Estados participantes destes processos. (MERCOCIUDADES, 2014).

Nesse passo, a Rede argumenta pela necessidade de ressignificação do espaço urbano a partir da redefinição do conceito de fronteiras. Defende serem os governos locais responsáveis por afirmar junto aos governos nacionais uma nova ideia de fronteira, não mais calcada na simples limitação do território e na garantia da segurança nacional. Ou seja, a Rede sustenta que as fronteiras devam passar a ser entendidas como caminhos de abertura à integração regional e à interconexão entre este espaço com os cenários local/nacional e global, em que se dê o estabelecimento de cooperação em políticas públicas que atendam a demandas da população envolvida. E isto deve enfocar especialmente o que toca à concretização do direito à saúde e ao combate à pobreza, gerando uma governança multinível para o estabelecimento de medidas aptas a proporcionar o desenvolvimento solidário e igualitário entre centro e periferias. Em função disso, é uma prioridade para a Rede Mercocidades, bem

\footnotetext{
${ }^{8}$ Esta Força-Tarefa foi formada a convite do Sr. Kadir Topbas, Prefeito de Istambul, Presidente da organização Cidades e Governos Locais Unidos (CGLU/UCLG), em função de este ter sido convocado como membro do Painel de Alto Nível (PAL/HPL) do Secretário Geral das Nações Unidas de pessoas eminentes na Agenda de Desenvolvimento Pós-2015. A ForçaTarefa reúne líderes de governos locais e regionais e organizações globais pertinentes. A sua finalidade é a construção conjunta de estratégia para contribuir com os debates de política internacional realizados no âmbito da Agenda Pós-2015, o acompanhamento das decisões tomadas na Conferência Rio+20 e delineamentos direcionados à Conferência Habitat III. Nesse sentido, destaca a ação dos governos locais e regionais nas questões de Prestação de Serviços Básicos (educação básica, saneamento, água, planejamento urbano e territorial, proteção ambiental, entre outros), que são essenciais para o desenvolvimento sustentável e a redução da pobreza, e de Coesão Territorial (que trata dos problemas de expansão decorrentes do aumento da urbanização), os quais não podem ser enfrentados de modo eficaz por organismos internacionais e governos centrais, distanciados do cotidiano das populações. Tendo em vista isso, a Rede Mercocidades foi chamada a fazer parte desta Força-Tarefa, juntamente com outras organizações representativas de governos locais e regionais. (GLOBAL TASKFORCE OF LOCAL AND REGIONAL GOVERNMENTS, 2016).
} 
como deve ser elevado a eixo fundamental de todos os países membros e associados a processos regionalistas, e a processos maiores de inserção global, a integração fronteiriça. Isso se justifica na medida em que é preciso sublinhar a importância da integração regional como elemento fundamental no processo de internacionalização das cidades, como marco de referência para a implementação de políticas tendentes ao desenvolvimento dos povos. (MERCOCIUDADES, 2014).

E, a Rede vem reforçando este posicionamento, o que vem sendo feito mediante a recém-criada Vice-Presidência de Integração Fronteiriça, exercida justamente pela cidade de Porto Alegre, coordenadora do trabalho que resultou no referido documento. Esta VicePresidência, em conjunto com a UT de mesmo tema, vem congregando as cidades fronteiriças membros da Rede para envidarem esforços em concretizar esta tarefa. (MERCOCIUDADES, 2016).

Diante disso, percebe-se que se iniciaram alguns passos para fomentar a integração fronteiriça, podendo-se realizar muitos outros, sendo importante a promoção de mais ações conjuntas pelos governos locais para seus projetos comuns, constituindo-se a Rede Mercocidades, com sua UT específica, adequado e viável instrumento para as cidades de fronteira qualificarem suas iniciativas nesta temática (GARCIA, 2013/2014, p. 25). A Rede, ao estar conectada, como visto na primeira seção, a diversas esferas institucionais do MERCOSUL, pode proporcionar maior visibilidade e alcance às demandas fronteiriças, a fim de consolidar sua presença na pauta de discussões e decisões do bloco definitivamente.

Nesse diapasão, ao inserir-se na Rede, as cidades podem dispor de um facilitador para o debate e cooperação em matéria transfronteiriça. Isto lhe permite construir mecanismos mais solidamente capacitados para coordenar suas atividades de cooperação descentraliza, concretizando parcerias estratégicas para o desenvolvimento local, por ações colaborativas nos espaços de fronteira (ALMEIDA PRADO, 2015, p. 77). Podem, assim, mediante sua participação na Rede, encontrar maior unidade e, com isso, maior força para garantir à sua participação no FCCR e no MERCOSUL mais efetividade, realizando concretamente projetos de melhoria das condições de vida das populações de fronteiras e, consequentemente, de toda a região.

\section{Considerações Finais}

A tendência hodierna de os atores subnacionais assumirem maior autonomia nas relações internacionais, para apresentarem e concretizarem seus interesses no ambiente 
global, serve de alerta para os organismos internacionais. Como visto no texto, esses atores demandam espaço para sua inserção, e os processos de integração regional se mostram aptos a acolhê-los.

A Rede Mercocidades, como um desses atores, aproximou-se do MERCOSUL, operando junto a este. Nesse passo, examinou-se como se dá esta relação, encontrando-se no bloco espaço institucionalizado para participação da Rede. Este espaço é o FCCR, em que a Rede preside o Comitê de Municípios. Contudo, como se trata de órgão meramente consultivo, isto dificulta os reflexos da atuação da Rede em termos de influência nas decisões tomadas pelo bloco. Apesar disso, a Rede pode utilizar-se da participação no referido Comitê, a fim de direcionar decisões do FCCR com relação ao encaminhamento de projetos de desenvolvimento regional ao FOCEM, fundo do MERCOSUL para financiamento deste tipo de projetos.

Além disso, a Rede tem envidado esforços no sentido de garantir articulação com outros órgãos do MERCOSUL, que trabalhem com temas comuns aos seus, como é o caso do ISM e da UPS, com os quais a Rede possui convênio de cooperação. Assim, a Rede tem encontrado espaços institucionais junto ao MERCOSUL para tentar, pela sua atuação, incluir demandas municipais na condução das atividades do bloco, ainda que tais espaços precisem de reforço político para ter um maior e efetivo impacto.

Nesse sentido, tendo em vista o caráter ainda centralizador da tomada de decisões do bloco, a Rede, ao se articular com outros espaços institucionais deste, incrementa as chances de que as demandas dos governos locais possam influenciar a adoção de políticas integracionistas. Isto é de extrema relevância no que tange à ampliação dos esforços para o desenvolvimento da questão fronteiriça.

Como visto na segunda seção do texto, o bloco dispõe, em sua institucionalidade, de poucos órgãos dedicados ao tema, o GAHIF e o GTIF, os quais apresentaram impacto reduzido e parca atuação desde seu estabelecimento. Para que os municípios possam adquirir maior influência na determinação de políticas de integração fronteiriça, auxiliando a desenvolvê-las no âmbito mercosulino, uma via importante e adequada parece ser o reforço da atuação da Rede Mercocidades. Esta, como foro de cooperação entre as cidades sul- americanas, pode dar maior visibilidade e coesão à atuação do FCCR e dos demais órgãos dedicados à temática transfronteiriça, pela adesão e participação de cada vez mais municípios em suas reuniões, projetos e programas. Isto fará com que, por estarem mais e melhor articulados, os governos locais passem a apresentar uma voz uníssona e mais forte, 
proporcionando condições mais adequadas de negociação e influência nas relações com os governos centrais que comandam o bloco.

Assim, a Rede pode contribuir ao reforço político do espaço institucional destinado aos entes subnacionais no MERCOSUL. Pode, portanto, auxiliar, pelas ações realizadas mediante sua UT especificamente dedicada à questão, a ampliar e aprofundar as discussões sobre o tema transfronteiriço no bloco, bem como a estabelecer projetos e ações concretas para o desenvolvimento das cidades de fronteira e da região como um todo.

\section{Referências}

ALMEIDA PRADO, Henrique Sartori de. A cooperação descentralizada e transfronteiriça no MERCOSUL: a construção de um regime simbólico. In: ESPÓSITO NETO, Tomaz; ALMEIDA PRADO, Henrique Sartori de. Fronteiras e relações internacionais. Curitiba: Íthala, p. 55-82, 2015.

ANDRADE E BARROS, Marinana. Atuação internacional dos governos subnacionais. Belo Horizonte: Del Rey, 2010.

BERMUDEZ TORRES, César Augusto. MERCOSUR Y UNASUR: Una mirada a la integración regional a comienzos del siglo XXI. Analisis Político, Bogotá, v.24, n. 72, p. 115-131, mai/ago. 2011.

BRASIL; PORTAL FEDERATIVO. Governos locais do Mercosul reativam Grupo de Trabalho de integração fronteiriça. 15/07/2015. Disponível em: http://www.portalfederativo.gov.br/noticias/destaques/governos-locais-do-mercosul-reativamgrupo-de-trabalho-de-integracao-fronteirica-1. Acesso em: 01 ago. 2015.

CASTELO BRANCO, Álvaro Chagas. A paradiplomacia como forma de inserção internacional de unidades subnacionais. Prismas: Dir., Pol.Pub. e Mundial., Brasília, v.4, n,

1, p. 48-67, jan/jul. 2007.

DE MATOS, Giovanna Arjonilla; STEFFEN, Nathalie Padovani. A rede Mercocidades e o Mercosul: atuação em rede através do FCCR. Conjuntura Internacional, Belo Horizonte, v.9, n. 5, p. 31 - 39, 2o sem. 2012.

DUCHACEK, Ivo D. Perforated sovereignties: toward a typology of new actors in international relations. In: MICHELMANN, H. J; SOLDATOS, P. Federalism and international relations: the role of subnational units. Nova York: Oxford University Press, p.

16-27, 1990.

FRONZAGLIA, M. L. Unidades Subnacionais: um estudo de caso sobre a cidade de São Paulo - de 2001 a 2004. Dissertação de Mestrado. Instituto de Filosofia e Ciências Humanas. Universidade de Campinas. Campinas, 2005.

GARCIA, Ronaldo. Mercocidades e a Integração Fronteiriça. Diálogo - Protagonismo Cidadão e Identidade Regional, 30ª Edição, p. 23-25, 2014. 
O Relevante Papel das Cidades na Integração Regional Sul- Americana: A Rede Mercocidades como via Propícia à Ressignificação dos Espaços Urbanos de Fronteira e ao Desenvolvimento da Integração

Fronteiriça

GLOBAL TASKFORCE OF LOCAL AND REGIONAL GOVERNMENTS. About Us. Disponível em: http://www.gtf2016.org/\#!about-us/c1qv7. Acesso em 22 mar. 2016.

HAFTECK, Pierre. An Introduction to Decentralized Cooperation: Definitions, Origens, and Conceptual Mapping. Public Administration and Development, n. 4, p. 333-345, Out./2003.

KLEIMAN, Alberto. Processo de Institucionalização de Mercocidades. Da REMI ao FCCR. In: MERCOCIDADES. 15 Años de Mercociudades. Rosario: Aquatint, p. 61-64, 2010.

LOSADA, Paula Ravanelli; SADECK, Bruno. O papel da fronteira na integração regional - o caso do consórcio intermunicipal de fronteira. In: ESPÓSITO NETO, Tomaz; ALMEIDA PRADO, Henrique Sartori de. Fronteiras e relações internacionais. Curitiba: Íthala, p. 37$53,2015$.

MERCOCIUDADES. Estatuto y Reglamento de Mercociudades. Disponível em: http://www.mercociudades.org/node/2273. Acesso em: 22 mar. 2016.
Autoridades.
Consejo.
Disponível

em:

http://www.mercociudades.org/node/2275\#consejo. Acesso em: 22 mar. 2016.

Unidades Temáticas. Disponível em: http://www.mercociudades.org/node/2286.

Acesso em: 22 mar. 2016.

Avanços e Proposta de Trabalho da Unidade de Participação Social do MERCOSUL. Disponível em: http://www.mercociudades.org/pt-br/node/4666. Acesso em: 22 ago. 2014.

; ISM. Convênio Marco de Cooperação entre o Instituto Social do MERCOSUL e a Rede Mercocidades. Disponível em: http://mercociudades.org/sites/portal.mercociudades.net/files/Convenio\%20de\%20Cooperaci \%C3\%B3n_Mercociudades_ISM_firmado\%205\%20nov_2012.pdf. Acesso em: 22 ago. 2014.

Mercocidades - $\quad$ Período 2013/2014. 2 Disponível em:

Informe da Secretaria Executiva e Secretaria Técnica Permanente de http://www.mercociudades.org/node/2108. Acesso em: 20 jun. 2015.

Ata da XVIII Cúpula das Mercocidades, realizada em Porto Alegre no ano de 2013. Disponível em: http://www.mercociudades.org/node/2131. Acesso em: 20 dez. 2014.

Documento de Referência da Rede Mercocidades para Global Taskforce e Habita III (ONU/Habitat). Porto Alegre, 2014.

MERCOSUL. CMC/Decisão n. 41/2004. Disponível em: http://www.mercosur.int/innovaportal/v/580/1/secretaria/decisiones_2004. Acesso em: 22 ago. 2014.

$$
\text { CMC/Decisão n. } \mathbf{0 5 / 2 0 0 2} \text { Disponível em: }
$$
http://www.mercosur.int/innovaportal/v/580/1/secretaria/decisiones_2002. Acesso em: 22 ago. 2014. 
. Em poucas palavras. Disponível em:

http://www.mercosur.int/t_generic.jsp? contentid=3862\&site=1\&channel=secretaria\&seccion $=2$. Acesso em: 22 ago. $2014 \mathrm{~b}$.

; FCCR. Regimento Interno do FCCR. Disponível em:

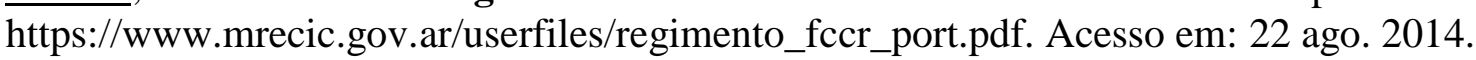

. Ata n. 01/2008 - VII Reunião de Coordenadores Nacionais do FCRR.

Disponível em: http://www.fccrmercosur.org/web/vii-reunion-de-coordinadores-del-fccr-17mar-2008/. Acesso em: 01 ago. 2015.

Plano de Ação 2013-2014. Disponível em: http://www.fccrmercosur.org/web/plan-de-accion/. Acesso em: 01 ago. 2015.

Ata da Primeira Reunião do Grupo de Trabalho de Integração Fronteiriça. Porto Alegre, 2015.

; FOCEM. O que é o FOCEM? Disponível em: http://www.mercosur.int/focem/index.php?id=que-es-el-focem. Acesso em: 22 ago. 2014.

; ISM. Institucional. Disponível em: http://ismercosur.org/pt-br/institucional/. Acesso em: 22 ago. 2014.

PRAZERES, Tatiana Lacerda. Por uma atuação constitucionalmente viável das unidades federadas brasileira. In: VIGEVANI, Tullo (Org.). A dimensão subnacional e as reações internacionais. São Paulo: Unesp, p. 283-312, 2004.

RODRIGUES, Gilberto Marcos Antonio. Política Externa Federativa. Análise de Ações Internacionais de Estados e Municípios Brasileiros. Tese de doutorado. PUC-SP. São Paulo, 2004.

SAUSI, José Luis Rhi; ODDONE, Nahuel. A cooperação transfronteiriça entre as unidades sub-nacionais do MERCOSUL. Tradução de Thauan Santos. Disponível em:http://www.paradiplomacia.org/upload/downloads/31b47f3b39a610539b7531841e5f2795 doc1port.pdf. Acesso em: 20 jun. 2015.

TAVARES, Rodrigo. Foreign Policy goes Local. Foreign Affairs, 09/10/2013. Disponível em: http://www.foreignaffairs.com/articles/140091/rodrigo-tavares/foreign-policy-goes-local. Acesso em: 10 out. 2013.

VAZ, Alcides Costa. O Relançamento do MERCOSUL. Boletim Meridiano 47, Brasília, n. 1, p. 3-4, jul. 2000. 